Check for updates

Cite this: Chem. Commun., 2019, 55, 11434

Received 31st July 2019,

Accepted 14th August 2019

DOI: $10.1039 / \mathrm{c} 9 \mathrm{cc} 05968 \mathrm{~g}$

rsc.li/chemcomm

\section{Self-templated synthesis of an orthoformate in,in-cryptand and its bridgehead inversion by dynamic covalent exchange $\uparrow$}

\author{
Henrik Löw, Elena Mena-Osteritz and Max von Delius (D)*
}

\begin{abstract}
We report the template-free dynamic covalent self-assembly of a small orthoformate cryptand, which appears to be driven by the formation of two sets of intramolecular, four-centre hydrogen bonds. In contrast to their nitrogen-bridgehead counterparts, orthoformate cryptands do not spontaneously invert, but require dynamic covalent exchange to do so.
\end{abstract}

The in,out-isomerism of macrocycles and cryptands has been examined in much detail during the second half of the last century. ${ }^{1}$ Early examples ${ }^{2}$ included katapinands, ${ }^{3}$ protonated azacryptands ${ }^{4}$ as well as phosphor-bridged ${ }^{5}$ macrocycles and cryptands. Mechanistically, bridgehead inversion was found to occur by homeomorphic isomerisation, ${ }^{1,2 a}$ which inverts the configuration at the bridgehead atoms by pulling one chain through the macrocycle defined by the other two chains. ${ }^{6}$ This process was found to either require protonation/deprotonation of the Brønsted basic bridgehead atoms or large ring sizes $(n>20) \cdot{ }^{1,2 a}$ To the best of our knowledge, there are no reports on the inversion of macrobicyclic architectures by dynamic covalent chemistry (DCC).

We have recently made use of the dynamic covalent reaction ${ }^{7}$ between orthoesters and diols ${ }^{8}$ to prepare a new class of monometallic cryptands. ${ }^{9}$ During extensive studies on the scope of these templated self-assembly reactions (Scheme 1a), ${ }^{9 a}$ we observed that orthoformates are unique outliers, because they are the only out,out-cryptands templated by the $\mathrm{Li}^{+}$ion (normally: $\mathrm{Na}^{+}$). Herein, we report a more fundamental facet of this outlier behaviour, namely that in the absence of metal ions, a remarkable in,incryptand is formed in a process that appears to be driven by intramolecular hydrogen bonds centred on the positively polarised hydrogen atoms of the orthoformate bridgeheads. With the metaltemplated out,out-cryptate and the self-templated in,in-cryptand

Institute of Organic Chemistry, University of Ulm, Albert-Einstein-Allee 11, 89081 Ulm, Germany. E-mail: max.vondelius@uni-ulm.de

$\dagger$ Electronic supplementary information (ESI) available: Experimental procedures, characterisation and spectral data, crystallographic data. CCDC 1876094 and 1876120. For ESI and crystallographic data in CIF or other electronic format see DOI: $10.1039 / \mathrm{c} 9 \mathrm{cc} 05968 \mathrm{~g}$
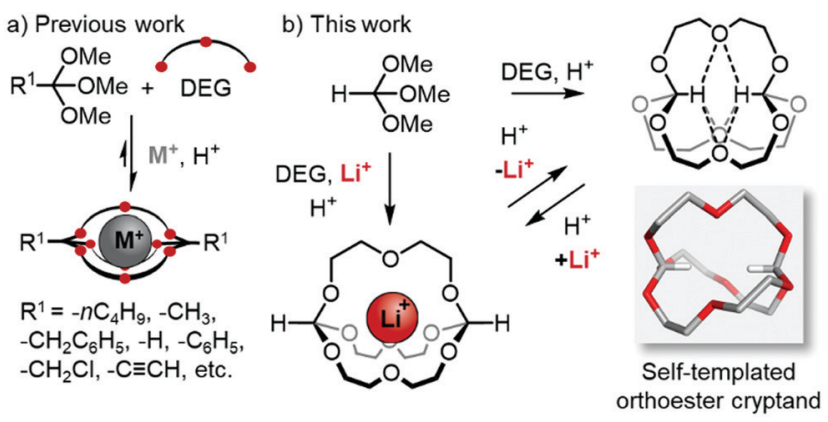

Scheme 1 (a) Previous work on the scope of self-assembled orthoester cryptands. (b) Syntheses of two orthoformate cryptands: $\mathrm{Li}^{+}$-templated out,out-cryptand, self-templated in,in-cryptand and their interconversion by dynamic covalent bridgehead inversion.

in hand, we were able to achieve inversion at the carbon bridgeheads by means of acid-catalysed dynamic covalent exchange (Scheme 1b).

The starting point for the present study was the unexpected observation that the reaction of trimethyl orthoformate and DEG with $1 \%$ TFA as catalyst in the absence of a metal template furnished orthoester cryptand $\boldsymbol{o}-\left(\mathbf{H}_{\mathbf{i n}}\right)_{\mathbf{2}} \mathbf{- 1 . 1 . 1}$ in $c a .50 \%$ isolated yield (Scheme 2). This result was surprising, because we had previously found $^{9 a}$ (Scheme 1a) that a suitable alkali metal template (e.g. Li or NaBArF) is strictly necessary to avoid the predominant formation of eight-membered ring products. ${ }^{9 a, b}$

Conveniently, we were able to obtain highly pure, crystalline material of $\boldsymbol{o}-\left(\mathbf{H}_{\text {in }}\right)_{2}-\mathbf{1 . 1 . 1}$ by simple washing with diethyl ether (see ESI $\dagger$ ). It occurred to us that the relatively clean formation of this particular cryptand from a dynamic combinatorial network comprising a multitude of other products may be a result of the formation of intramolecular hydrogen bonds between the bridgehead hydrogen atoms and the central oxygen atoms in the DEG chains. According to this hypothesis, $\boldsymbol{o}-\left(\mathbf{H}_{\text {in }}\right)_{2}-\mathbf{- 1 . 1 . 1}$ would not be formed by a metal-template effect but rather be "self-templated" (vide infra for X-ray crystallography).

To test this hypothesis, we attempted the transformation of out,out-cryptand $\boldsymbol{o}-(\mathbf{H})_{2}-\mathbf{1 . 1 . 1}$ into in,in-cryptand $\boldsymbol{o}-\left(\mathbf{H}_{\text {in }}\right)_{2}-\mathbf{1 . 1 . 1}$. 


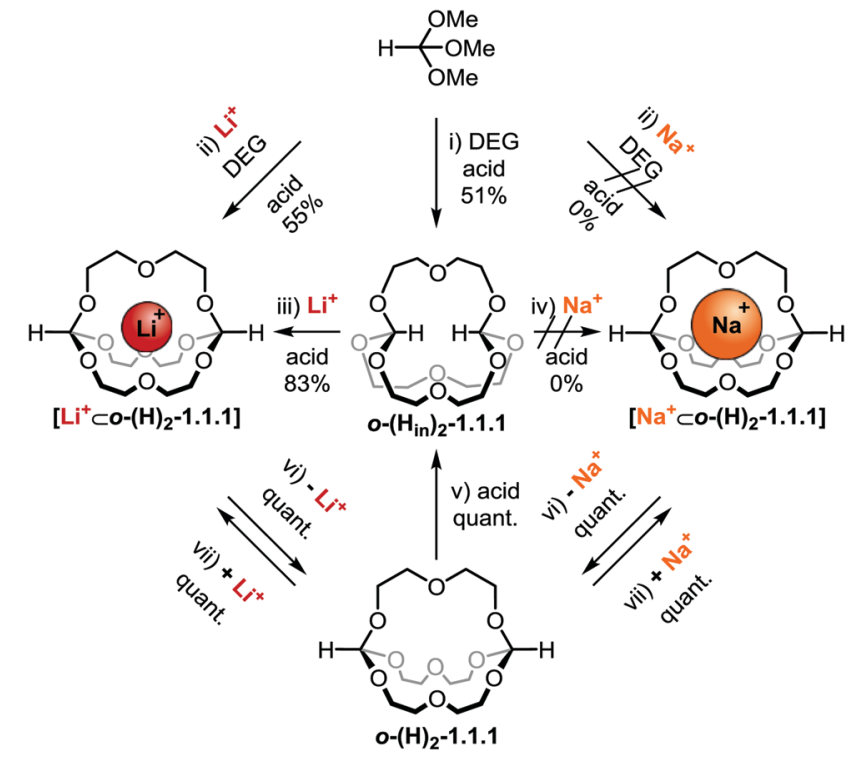

Scheme 2 Interconversion of self-templated in,in-and metal-templated out,out-orthoformate cryptands. Percent values indicate isolated yields. Reaction conditions: (i) trimethyl orthoformate, diethylene glycol and TFA in $\mathrm{CHCl}_{3}, 5 \AA$ molecular sieves (MS), $3 \mathrm{~d}$. (ii) Lithium tetrakis[3,5bis(trifluoromethyl)phenyl]borate (LiBArF) or NaBArF, trimethyl orthoformate, diethylene glycol and TFA in $\mathrm{CHCl}_{3}, 5 \AA \mathrm{MS}, 3 \mathrm{~d}$. (iii) o- $\left(\mathrm{H}_{\text {in }}\right)_{2}-1.1 .1$, LiBArF and TFA in $\mathrm{CHCl}_{3}, 10$ min. (iv) $0-\left(\mathrm{H}_{\text {in }}\right)_{2}-1.1 .1, \mathrm{NaBArF}$ and TFA in $\mathrm{CHCl}_{3}, 3 \mathrm{~d}$. (v) o-(H) $)_{2}-1.1 .1$ and TFA in $\mathrm{CHCl}_{3}, 10$ min. (vi) $\left[\mathrm{Li}^{+} \subset \mathrm{O}-(\mathrm{H})_{2}-1.1 .1\right]$ or $\left[\mathrm{Na}^{+} \subset \mathrm{O}^{-}\right.$ (H) $\left.)_{2}-1.1 .1\right]$ and chloride-loaded anion exchange resin (Lewatit MP-68) in $\mathrm{CHCl}_{3}, 12$ h. (vii) o-(H) $-\mathbf{- 1 . 1 . 1}$ and LiBArF or NaBArF in $\mathrm{CH}_{3} \mathrm{CN}, 5$ min. For further details, see ESI. $\dagger$

A significant difference in free energy between these stereoisomers would suggest that one of the two isomers is subject to thermodynamic stabilisation. While the thermal inversion did not occur under the tested conditions $\left(150{ }^{\circ} \mathrm{C}, \mathrm{DMF} ; 200{ }^{\circ} \mathrm{C}\right.$, neat), we found that bridgehead inversion was indeed possible and highly efficient under constitutionally dynamic conditions. As shown in Scheme 2 (bottom), addition of catalytic amounts of acid to $\boldsymbol{o}-(\mathbf{H})_{2}-\mathbf{1 . 1 . 1}$ resulted in the quantitative formation of $\boldsymbol{o}-\left(\mathbf{H}_{\mathbf{i n}}\right)_{2} \mathbf{- 1 . 1 . 1}$ within $5 \mathrm{~min}$.

To demonstrate that the inversion from the out,out- to the in,in-isomer is not due to strain in the out,out-cryptand, we also studied the inversion in the opposite direction. As shown in Scheme 2 (left hand side), this transformation from self-templated $\boldsymbol{o}-\left(\mathbf{H}_{\text {in }}\right)_{2}-\mathbf{1 . 1 . 1}$ to metal-templated $\left[\mathbf{L i}^{+} \subset \boldsymbol{o}-(\mathbf{H})_{2}-\mathbf{1 . 1 . 1}\right]$ was also feasible. Only $10 \mathrm{~min}$ after $1 \%$ acid catalyst and one equivalent LiBArF template was added, the desired out,out-cryptand $\left[\mathbf{L i}^{+} \subset \boldsymbol{o}\right.$ $(\mathbf{H})_{2}$-1.1.1] was obtained in $83 \%$. Again, we tested whether a (thermal) homeomorphic isomerisation could be induced by the addition of one equivalent LiBArF as metal template and heating $\left(80{ }^{\circ} \mathrm{C}, \mathrm{MeCN}\right)$. However, such an inversion did not occur, demonstrating that one DEG chain cannot be "pulled through" the cryptand to invert the configuration of the bridgeheads. ${ }^{1,2 a}$

Having obtained a preliminary understanding of self-templation and bidirectional bridgehead inversion (left hand side of Scheme 2), we decided to investigate the anomalous ${ }^{9 a}$ metal ion affinity of $\boldsymbol{o}-(\mathbf{H})_{2}-\mathbf{1 . 1 . 1}$ in more detail (right hand side of Scheme 2).
To this end, we initially found that $\mathrm{Na}^{+}$exchange between $\boldsymbol{o}-(\mathbf{H})_{2} \mathbf{- 1 . 1 . 1}$ and the bulk is fast on the NMR timescale in chloroform, which is in stark contrast to all other previously investigated orthoester cryptands. ${ }^{9 a, c, 10}$ This finding allowed us, for the first time, to study the thermodynamics of sodium binding in the solvent used for the self-assembly reactions. Therefore, we performed triplicate ${ }^{1} \mathrm{H}$ NMR titrations in chloroform and fitted the binding isotherms with a 1:1 stoichiometric model.§ These experiments revealed that the binding of sodium to $\boldsymbol{o}-(\mathbf{H})_{2}-\mathbf{1 . 1 . 1}$ in chloroform is rather weak $\left(K_{\mathrm{a}}=500 \mathrm{M}^{-1} \pm 100\right.$, see ESI $\left.\dagger\right)$, indeed about two orders of magnitude weaker than the interaction between $\mathrm{Na}^{+}$and the methyl-substituted cryptand $\boldsymbol{o}-\left(\mathbf{C H}_{3}\right)_{2}-\mathbf{1 . 1 . 1}{ }^{10}$ in the more polar solvent acetonitrile. This explains why we were neither able to self-assemble $\left[\mathbf{N a}^{+} \subset \boldsymbol{o}-(\mathbf{H})_{2}-\mathbf{1 . 1 . 1}\right]$ from a mixture of orthoester and diol (Scheme 2, top right) nor obtain the same compound by dynamic covalent bridgehead inversion (Scheme 2, centre right). Nevertheless, we were able to isolate $\left[\mathrm{Na}^{+} \subset \boldsymbol{o}-(\mathbf{H})_{2^{-}}\right.$ 1.1.1] by addition of one equivalent of NaBArF to empty $\boldsymbol{O}-(\mathbf{H})_{2}-$ 1.1.1 in acetonitrile (Scheme 2, bottom right).

To obtain structural insights into $\boldsymbol{o}-\left(\mathbf{H}_{\mathrm{in}}\right)_{2} \mathbf{- 1 . 1 . 1}$ by X-ray crystallography, we grew single crystals of this compound by slow evaporation of diethyl ether (space group $P 2_{1} / c$ ). The in,in-cryptand has $C_{3 \mathrm{~h}}$-symmetry and, as expected, does not feature an alkali metal ion at the centre of the cavity (Chart 1a). Instead, both methine hydrogen atoms point directly into the cavity, while the two orthoester carbon atoms have a distance of $4.5 \AA$ A. Although $\mathrm{X}$-ray diffraction is not suited to elucidate the precise location of hydrogen atoms, we performed a difference electron density map at a late stage of the structural refinement (OLEX) ${ }^{11}$ in order to place the methine hydrogen atoms more precisely in the atomistic model. Keeping this limitation in mind, the hydrogen positions are providing a valuable basis for structural insights. Both the approximate $\mathrm{H} \cdots \mathrm{O}$ distances $(2.4$ to $2.5 \AA$, sum of van der Waals radii $\left.{ }^{12}=2.6 \AA\right)$ and the hydrogen bond angles ( $\mathrm{C}-\mathrm{H} \cdots \mathrm{O}$ angles: 119 to $122^{\circ}$ ) point towards the formation of two four-centre hydrogen bonds between the two hydrogen and the three oxygen atoms (Chart 1b). The two bridgehead hydrogen atoms have an approximate distance of $2.5 \AA$, which is significantly above the sum of van der Waals radii ${ }^{12}(2.2 \AA)$. An analysis of all $\mathrm{O}-\mathrm{C}-\mathrm{O}$ angles of the two orthoester bridgeheads reveals a very narrow distribution $\left(107.5^{\circ}\right.$ to $\left.108.2^{\circ}\right)$, which seems unlikely to stem only from packing effects and hence provides support for a rigidification of the molecule by hydrogen bonding.

Additionally, we were able to grow single-crystals of the $\left.\left[\mathrm{Na}^{+} \subset \boldsymbol{O} \text {-(H) }\right)_{2}-\mathbf{1 . 1 . 1}\right]$ cryptate and obtain high-quality X-ray crystallographic data (space group $P 2_{1} 2_{1} 2_{1}$, Chart $1 \mathrm{c}$ ). While the previously reported complex $\left[\mathbf{L i}^{+} \subset \boldsymbol{O}-(\mathbf{H})_{2}-\mathbf{1 . 1 . 1}\right]$ featured only five $\mathrm{Li}-\mathrm{O}$ bonds (1.96 to $2.23 \AA$, Chart $1 \mathrm{~d}),{ }^{9 a}$ in $\left[\mathrm{Na}^{+} \subset \boldsymbol{o}-(\mathbf{H})_{2}-\mathbf{- 1 . 1}\right.$.1] eight $\mathrm{Na}-\mathrm{O}$ contacts are observed (2.24 to $2.68 \AA$ ), and one orthoester oxygen does not bind the sodium ion (3.61 $\AA$; highlighted in Chart 1c). Although this could in principle be a packing effect, we believe this stems from the previously mentioned outlier behaviour of orthoformate cryptands and reflects the low affinity of $\boldsymbol{o}-(\mathbf{H})_{2}$ 1.1.1 for the sodium ion.

To explain the anomalous $\mathrm{Li}^{+} / \mathrm{Na}^{+}$affinity of orthoformate cryptands (Chart 1e), a detailed analysis of the torsion angles 
a) $o-\left(H_{\text {in }}\right)_{2}-1.1 .1$

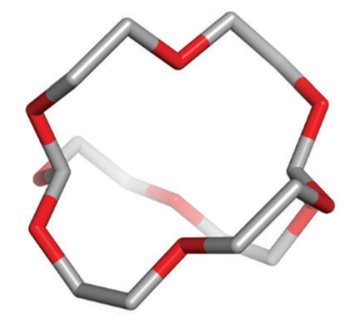

c) $\left[\mathrm{Na}^{+} \mathrm{CO}-(\mathrm{H})_{2}-1.1 .1\right]$

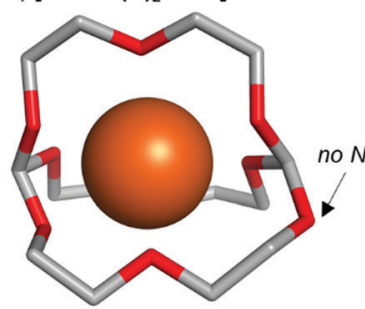

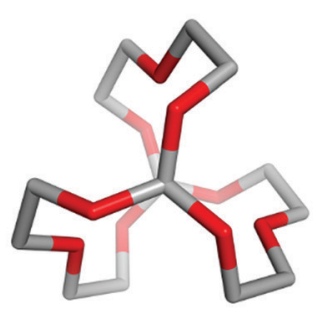

d) $\left[L i^{+} \subset O-(H)_{2}-1.1 .1\right]^{9 a}$

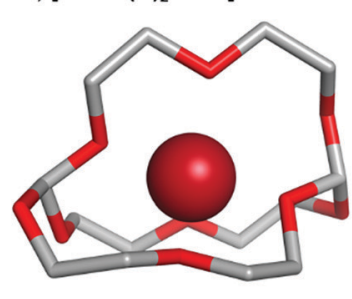

b) Approximate $\mathrm{H}$-bond distances and angles in $\mathrm{o}-\left(\mathrm{H}_{\text {in }}\right)_{2}-1.1 .1$ (X-ray!)
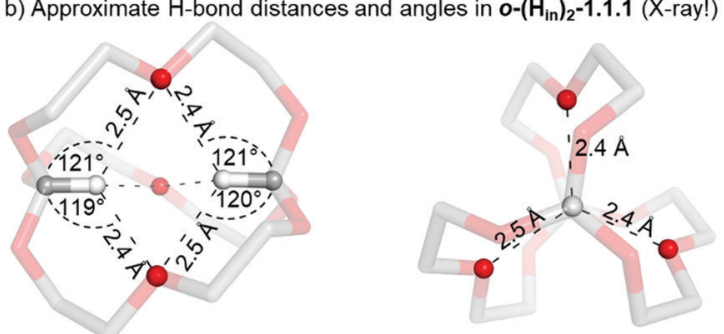

e) Torsion

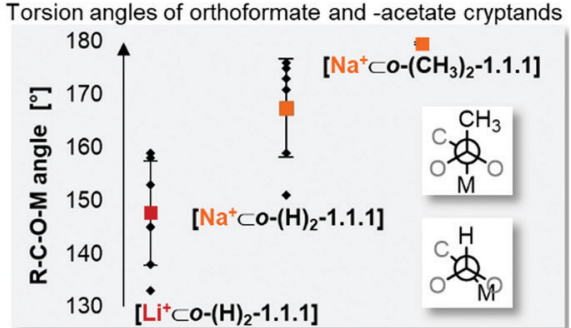

Chart 1 Solid-state structures of self-templated orthoformate cryptand and two metal-templated orthoformate cryptates. Hydrogen atoms, anions, solvent and disorder (where applicable) are omitted for clarity. Metal ions are displayed at $100 \%$ of effective ionic radius. ${ }^{13}$ (a) Single crystals were obtained by slow evaporation of diethyl ether. Crystal system: monoclinic. (b) Approximate intramolecular hydrogen bond distances and angles in $\mathbf{0}-\left(\mathbf{H}_{\text {in }}\right)_{\mathbf{2}}-\mathbf{1 . 1 . 1}$ (values received from $\mathrm{X}$-ray crystallography). Oxygen and hydrogen atoms involved in intramolecular hydrogen bonding are highlighted. $\mathrm{H} \ldots \mathrm{O}$ distance: 2.4-2.5 A. C $-\mathrm{H} \ldots \mathrm{O}$ angles: $119-122^{\circ}$. (c) Single crystals were obtained by the layering method (hexane/chloroform). Crystal system: orthorhombic. (d) The solid-state structure of $\left[\mathrm{Li}^{+} \subset \mathbf{O}-(\mathbf{H})_{2}-\mathbf{1 . 1 . 1}\right]$ was reported previously ${ }^{9 a}$ and is shown for comparison. (e) Comparison of average $\mathrm{R}-\mathrm{C}-\mathrm{O}-\mathrm{M}$ torsion angles (coloured dots) of orthoformate and orthoacetate cryptands, including standard deviation and corresponding Newman projections. For further details, see ESI.†

(R-C-O-M dihedrals; $\mathrm{R}=\mathrm{H}$ or $\mathrm{CH}_{3} ; \mathrm{M}=\mathrm{Li}$ or $\mathrm{Na}$ ) was carried out. The average torsion angles in both orthoformate cryptands are significantly smaller with $168^{\circ}$ for $\left[\mathrm{Na}^{+} \subset \boldsymbol{O}-(\mathbf{H})_{2}-\mathbf{1 . 1 . 1}\right]$ and $148^{\circ}$ for $\left[\mathbf{L i}^{+} \subset \boldsymbol{O}-(\mathbf{H})_{2}-\mathbf{1 . 1 . 1}\right]$, when compared with the $180^{\circ}$ found in $\left[\mathbf{N a}^{+} \subset \boldsymbol{o}-\left(\mathbf{C H}_{3}\right)_{2}-\mathbf{1 . 1 . 1}\right] .{ }^{9 b}$ The most striking result is the extremely narrow distribution of torsion angles around $180^{\circ}$ in the orthoacetate cryptate, which was confirmed in at least three additional orthoacetate cryptands ${ }^{9 c}$ (see ESI $\dagger$ ). Hence, the antirelationship between the $\mathrm{CH}_{3}$ group and the $\mathrm{Na}^{+}$ion seems to be strongly preferred in orthoacetate, but not orthoformate cryptands. This preference, which is likely due to a stereoelectronic effect, ${ }^{14}$ results in orthoacetate cages being effectively larger and more rigid than orthoformate cages and thus explains the observed cation selectivities.

In conclusion, we have described the template-free synthesis of $\boldsymbol{o}-\left(\mathbf{H}_{\mathbf{i n}}\right)_{2} \mathbf{- 1 . 1 . 1}$, which to the best of our knowledge is the smallest organic cage compound ${ }^{15}$ prepared to date by reversible covalent reactions. ${ }^{16} \mathrm{X}$-ray crystallographic evidence tentatively supports our hypothesis that the process is thermodynamically driven by the formation of unusual intramolecular hydrogen bonds involving the bridgehead methine hydrogen atoms. Moreover, we demonstrated that bridgehead inversion occurs readily under conditions of dynamic covalent exchange.

This work was supported by the European Union (ERCstg 802428 "SUPRANET") and the Deutsche Forschungsgemeinschaft (Emmy-Noether grant DE1830/2-1). We gratefully acknowledge Lanxess for a donation of Lewatit anion exchange resin. We thank Magdalena Heiland for experimental work carried out as part of her Master program and Bernhard Müller for assistance with X-ray crystallography.

\section{Conflicts of interest}

There are no conflicts to declare.

\section{Notes and references}

$\ddagger$ Removal of the metal from $\left[\mathbf{L i}^{+} \subset \mathbf{o}-(\mathbf{H})_{2}-\mathbf{1 . 1 . 1}\right]$ to $\boldsymbol{o}-(\mathbf{H})_{2}-\mathbf{1 . 1 . 1}$ can be achieved quantitatively by treatment with anion exchange resin $(\mathrm{Cl}$ form, for further details see $\mathrm{ESI} \dagger$ ).

$\S$ Data fitted on the website www.supramolecular.org (95\% confidence interval, original data is available for download, see ESI $\dagger$ ).

1 R. W. Alder and S. P. East, Chem. Rev., 1996, 96, 2097-2112.

2 (a) C. H. Park and H. E. Simmons, J. Am. Chem. Soc., 1968, 90, 2429-2431; (b) J.-M. Lehn, Angew. Chem., Int. Ed. Engl., 1988, 27, 89-112; (c) P. G. Gassman and R. P. Thummel, J. Am. Chem. Soc., 1972, 94, 7183-7184; (d) P. G. Gassman, S. R. Korn and R. P. Thummel, J. Am. Chem. Soc., 1974, 96, 6948-6955.

3 (a) C. H. Park and H. E. Simmons, J. Am. Chem. Soc., 1968, 90, 2431-2432; (b) R. A. Bell, G. G. Christoph, F. R. Fronczek and R. E. Marsh, Science, 1975, 190, 151-152; (c) S. O. Kang, J. M. Llinares, V. W. Day and K. Bowman-James, Chem. Soc. Rev., 2010, 39, 3980-4003.

4 (a) P. B. Smith, J. L. Dye, J. Cheney and J.-M. Lehn, J. Am. Chem. Soc., 1981, 103, 6044-6048; (b) B. Pool, S. Balalaie, A. Kunze, G. Schilling, P. Bischof and R. Gleiter, Eur. J. Org. Chem., 2004, 2812-2817; (c) P. Morehouse, M. A. Hossain, J. M. Llinares, D. Powell and K. Bowman-James, Inorg. Chem., 2003, 42, 8131-8133; (d) L. R. MacGillivray and J. L. Atwood, J. Org. Chem., 1995, 60, 4972-4973; (e) L. R. MacGillivray and J. L. Atwood, Angew. Chem., Int. Ed. Engl., 1996, 35, 1828-1830.

5 (a) R. W. Alder, Tetrahedron, 1990, 46, 683-713; (b) R. W. Alder and D. Read, Angew. Chem., Int. Ed., 2000, 39, 2879-2882; (c) R. W. Alder, J. Chem. Soc., Perkin Trans. 2, 2001, 288-295.

6 (a) M. Stollenz, N. Bhuvanesh, J. H. Reibenspies and J. A. Gladysz, Organometallics, 2011, 30, 6510-6513; (b) M. Stollenz, D. Taher, N. Bhuvanesh, J. H. Reibenspies, Z. Baranová and J. A. Gladysz, Chem. Commun., 2015, 51, 16053-16056; (c) R. W. Alder, E. Honegger, A. B. Mcewen, R. E. Moss, E. Olefirowicz, P. A. Petillo, R. B. Sessions, G. R. Weisman, J. M. White and Z. Yang, J. Am. Chem. Soc., 1993, 115, 
6580-6591; (d) A. H. Haines and P. Karntiang, J. Chem. Soc., Perkin Trans. 1, 1979, 2577-2587; (e) M. Saunders and N. Krause, J. Am. Chem. Soc., 1990, 112, 1791-1795; $(f)$ R. S. Wareham, J. D. Kilburn, D. L. Turner, N. H. Rees and D. S. Holmes, Angew. Chem., Int. Ed. Engl., 1995, 34, 2660-2662.

7 (a) P. T. Corbett, J. Leclaire, L. Vial, K. R. West, J.-L. Wietor, J. K. M. Sanders and S. Otto, Chem. Rev., 2006, 106, 3652-3711; (b) J. Li, P. Nowak and S. Otto, J. Am. Chem. Soc., 2013, 135, 9222-9239; (c) Y. Jin, C. Yu, R. J. Denman and W. Zhang, Chem. Soc. Rev., 2013, 42, 6634-6654; (d) S. Otto, R. L. E. Furlan and J. K. M. Sanders, Curr. Opin. Chem. Biol., 2002, 6, 321-327; (e) R. C. Brachvogel and M. von Delius, Eur. J. Org. Chem., 2016, 3662-3670; ( $f$ ) Q. Ji, R. C. Lirag and O. S. Miljanić, Chem. Soc. Rev., 2014, 43, 1873-1884; $(g)$ A. Herrmann, Chem. Soc. Rev., 2014, 43, 1899-1933; (h) A. Wilson, G. Gasparini and S. Matile, Chem. Soc. Rev., 2014, 43, 1948-1962.

8 R.-C. Brachvogel and M. von Delius, Chem. Sci., 2015, 6, 1399-1403. 9 (a) H. Löw, E. Mena-Osteritz and M. von Delius, Chem. Sci., 2018, 9, 4785-4793; (b) R.-C. Brachvogel, F. Hampel and M. von Delius, Nat. Commun., 2015, 6, 7129; (c) O. Shyshov, R. C. Brachvogel, T. Bachmann,
R. Srikantharajah, D. Segets, F. Hampel, R. Puchta and M. von Delius, Angew. Chem., Int. Ed., 2017, 56, 776-781; (d) X. Wang, O. Shyshov, M. Hanzevacki, C. M. Jäger and M. von Delius, J. Am. Chem. Soc., 2019, 141, 8868-8876.

10 R.-C. Brachvogel, H. Maid and M. von Delius, Int. J. Mol. Sci., 2015, 16, 20641-20656.

11 O. V. Dolomanov, L. J. Bourhis, R. J. Gildea, J. A. K. Howard and H. Puschmann, J. Appl. Crystallogr., 2009, 42, 339-341.

12 R. S. Rowland and R. Taylor, J. Phys. Chem., 1996, 100, 7384-7391.

13 R. D. Shannon, Acta Crystallogr., Sect. A: Found. Adv., 1976, 32, 751-767.

14 I. V. Alabugin, Stereoelectronic Effects: A Bridge Between Structure and Reactivity, John Wiley \& Sons Ltd, Chichester, 2016.

15 (a) J. Rodríguez, J. Mosquera, J. R. Couceiro, J. R. Nitschke, M. E. Vázquez and J. L. Mascareñas, J. Am. Chem. Soc., 2017, 139, 55-58; (b) M. Kolodziejski, A. R. Stefankiewicz and J.-M. Lehn, Chem. Sci., 2019, 10, 1836-1843; (c) W. Drozdz, C. Bouillon, C. Kotras, S. Richeter, M. Barboiu, S. Clément, A. R. Stefankiewicz and S. Ulrich, Chem. - Eur. J., 2017, 23, 18010-18018.

16 A. Maymounah and O. Š. Miljanić, Chem. Commun., 2018, 54, 11989-11997. 